\title{
Primary care system outdated and inconvenient for many millennials
}

\author{
n Cite as: CMAJ 2018 December 3;190:E1430-1. doi: 10.1503/cmaj.109-5688
}

Posted on cmajnews.com on Nov. 15, 2018.

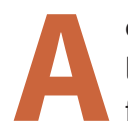
ccording to recent surveys, millennials are less likely to have family physicians than people from other generations. In the United States, about $33 \%$ of millennials don't have family doctors, compared to $15 \%$ for people aged 50-64, according to a 2017 survey. In Canada, those aged 18-34 are the most likely not to have family doctors, according to Statistics Canada.

Lack of access is one reason. Both in Canada and the US, a shortage of family doctors is forcing young people to cobble together alternatives. But convenience is also part of the picture, according to experts. A mix of urgent care centres, walk-in clinics and health care apps offer the immediacy that young people have become accustomed to in the Uber era.

"My own kids sometimes ask, 'Why shouldn't I just go to a walk-in?'” said Dr. David Price, chair of family medicine at McMaster University. "Society has changed. It's much more fast-paced ... our primary care medical system has not evolved with the changing times and that's why you're starting to see that disconnect."

Dr. Ali Damji, a family medicine resident at Credit Valley Hospital in Mississauga, said "young people don't always see the value of having that relationship with the family doctor." That's partly because the family physician model can be inconvenient. "People get shocked when they have to wait 20 minutes on the phone to get an appointment; it flies in the face of what young people are used to in every aspect of their lives," he said.

Another complication is that millennials move frequently for work or studies, which can make going to one family doctor difficult. "Who stays in one place for 20 to 30 years?" said Megan Kinch, a 36-year-old in Toronto, who recently signed up with a family health team but went without a family doctor for a decade. "The idea that you get a doctor who stays with you and follows you for the rest of your life is outdated."

Kinch says part of the reason she didn't feel the need to have a family doctor

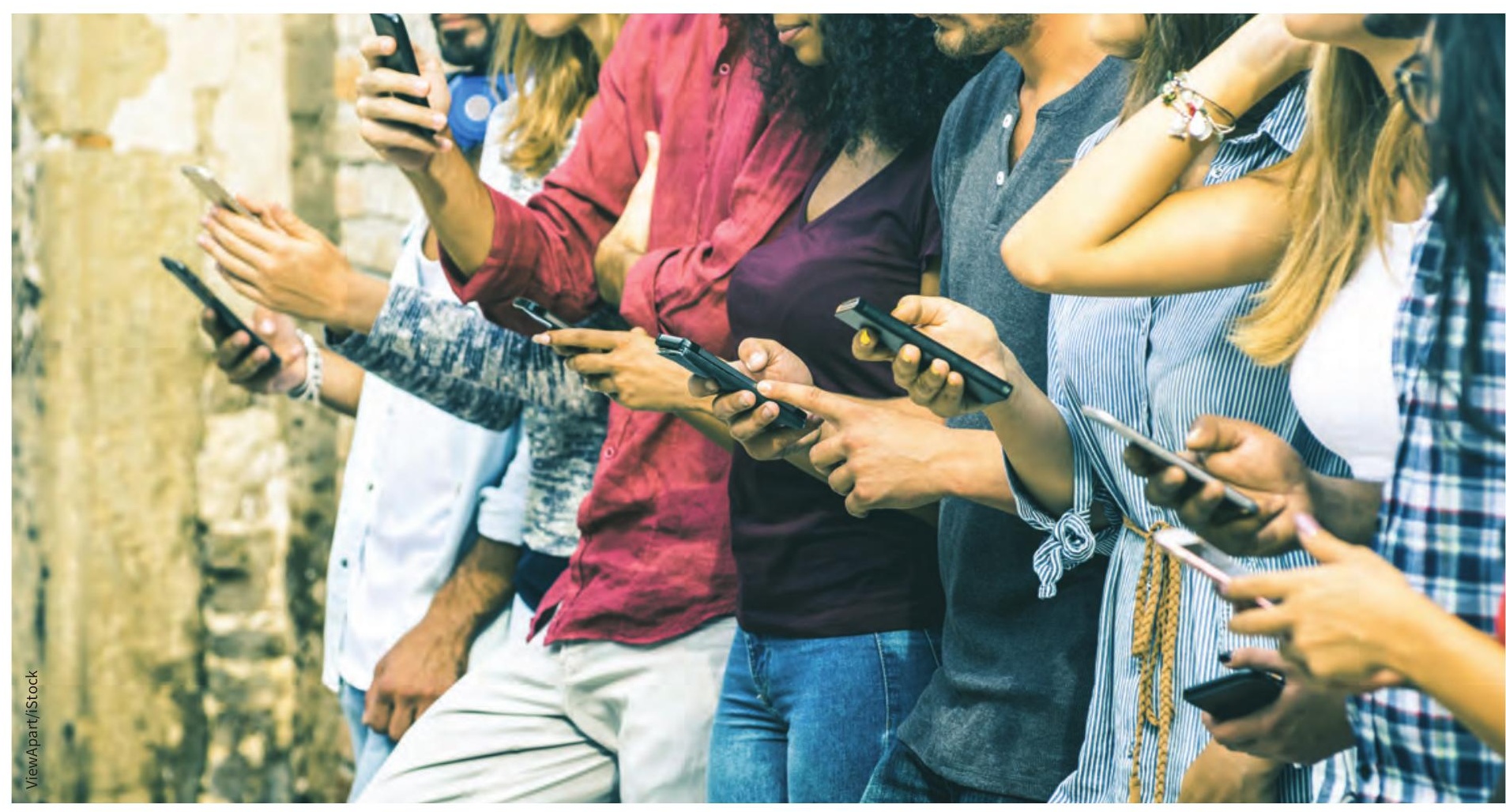

There is a growing disconnect between the family doctor model of health care delivery and the speed and convenience millennials expect for services. 
follow her through the system is that she's used to doing her own research and advocacy. "I overly educate myself in medical conditions," said Kinch, who recently changed her career path from academia to construction.

According to Price, Canada's primary care system needs to evolve to better serve young people, who often get stuck without a family doctor because of a recent move. "People should have instant, easy, ready access to a primary care provider who will seem them for as long as they're there," he said.

That young people tend to see medical care for acute rather than chronic issues also factors into the trend. Heather Van Mil, a marketing writer in Halifax in her mid-30s, said she and her family members are currently on a waitlist for a family doctor. She tried harder to get a family doctor since she developed chronic conditions.
"When I was healthy, it didn't matter to me to see a family doctor or not," she said. "Now, I want a GP who can see the big picture."

Dr. Tara Kiran, a family physician and researcher in primary care reforms at St. Michael's Hospital in Toronto, said she's sad to hear that young patients are being pushed, and to some degree pulled, out of the family doctor model. "Continuity of care is one of the measures that most strongly relates to good outcomes - better screening, better care, less use of [emergency departments] and overall better outcomes," said Kiran. She pointed out that relational continuity, or seeing the same provider, is associated with better health outcomes than informational continuity, or seeing providers who have access to one's health records.

"Medicine is more than just health problems; it's about relating to and work- ing with the person in front of you," she said. She noted that a patient's socioeconomic background, personal values and cultural beliefs often factor into medical decisions, so there's benefit to getting to know a patient over time. "If medicine was all about algorithms that related to disease, you wouldn't need a person to treat you."

Damji recommends that young people build that relationship so that it's there when they need it. "If you are seeing a regular doctor that you have a strong relationship with, you're going to feel more comfortable communicating with them, and they're going to better understand not just your health needs, but your social needs and the context that you live in, and all of that plays a huge role in someone's health."

Wendy Glauser, Toronto, Ont. 